\title{
Endodontic Retreatment of A Mandibular Canine with Two Roots and Two Canals CBCT
}

\author{
Rawan Almobarraz
}

Knowledge of root canal anatomy is an important part of root canal treatment. Mandibular canines usually contain one root with one canal, but anatomical variation may be seen. This paper describes a non-surgical root canal retreatment of mandibular canine with two roots and two separate canals. Clinicians must be able to identify the different variations to be able to successfully diagnose and manage their cases.

KEY WORDS: Endodontics; retreatment; canine; two roots; two canals

HOW TO CITE: Almobarraz R. Endodontic retreatment of a mandibular canine with two roots and two canals. J Pak Dent Assoc 2019;28(2):98-100.

DOI: https://doi.org/10.25301/JPDA.282.98

Received: 20 January 2019, Accepted: 14 February 2019

\section{INTRODUCTION}

$\mathrm{T}$ he mandibular canine is an important tooth in the dental arch. It's long and stable root gives it an advantage of being useful in giving support in a prosthesis due to its proprioceptive properties that guides the masticatory function and its role in occlusal guidance during the eccentric movements and posterior disocclusion. ${ }^{1}$ Mandibular canine is known for its one root and single canal. Variation may occur but is uncommon. The studies of Greene, Hess and Vertucci revealed $13 \%, 15 \%$ and $18 \%$ of two canals in a single root of mandibular canines respectively ${ }^{2}$, but the occurrence of two roots and even more than two canals is rare, ranging from 1 to $5 \% .{ }^{3}$ Pécora JD et al also studied the internal anatomy, the direction and the number of roots of the mandibular canines. The study was done on 830 mandibular canines, and the results showed that $98.3 \%$ had only one root and of these $97.2 \%$ had one canal and one opening orifice, $4.9 \%$ two canals and one orifice, $1.2 \%$ two canals and two orifices. Two canals and two roots were present in only $1.7 \%$ of the cases. ${ }^{4}$ The aim of endodontic treatment is to eliminate the infection from the root canal and to prevent the reinfection. ${ }^{5}$ Knowledge of the root canal anatomy contributes to the success of the treatment. This article reports a clinical case of nonsurgical endodontic retreatment of mandibular canine with two roots and two canals.

\section{CASE REPORT}

A 43-year-old female patient with no relevant past

Undergraduate Dental Student, Department of College of Dentistry, King Saud Univeristy Corresponding author: "Rawan Almobarraz” < RAlmobarraz@gmail.com > medical history was referred to the clinical endodontic undergraduate course for retreatment of lower right canine. History of treatment was done 8 years ago. Past dental history showed multiple root canal treatments and restorations. Preoperative periapical radiograph of tooth number \#43 showed mesial and distal caries, under filled obturation, periapical lesion, and widening of the PDL [Figure 1]. Upon clinical examination, the tooth was negative to percussion and palpation. With thermal testing, the tooth showed negative response. Tooth was diagnosed as previously treated with asymptomatic apical periodontitis. No mobility or deep pockets were found and the access cavity was closed with composite. The endodontic treatment plan was nonsurgical root canal retreatment.

From the periapical radiograph, a second root was suspected. To confirm this, further radiographic imaging using small field of view CBCT was taken after gutta percha removal and

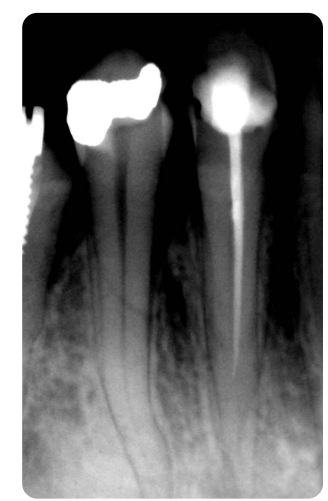

Figure 1: Periapical radiograph showing tooth \#43 with showed mesial caries and under filled and widening of the PDL obturation, periapical lesion, the tooth showed two separate roots with two separate canals [Figure 2]. The treatment was scheduled and initiated after obtaining a written informed consent from the patient.

Local anesthesia (2\% Xylocaine with 1: 80, 000 epinephrine) was introduced through infiltration and the tooth was isolated with a rubber dam using Ivory 9 clamp. Composite restoration from the previous access cavity was removed with a long shank round bur and the lingual orifice was located. To locate the buccal canal, the cavity was 


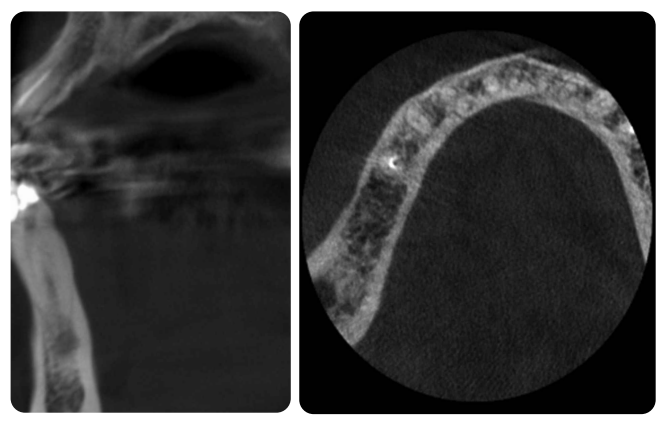

Figure 2: (a) CBCT showing sagittal section of the tooth \#43 with two roots (b) axial section
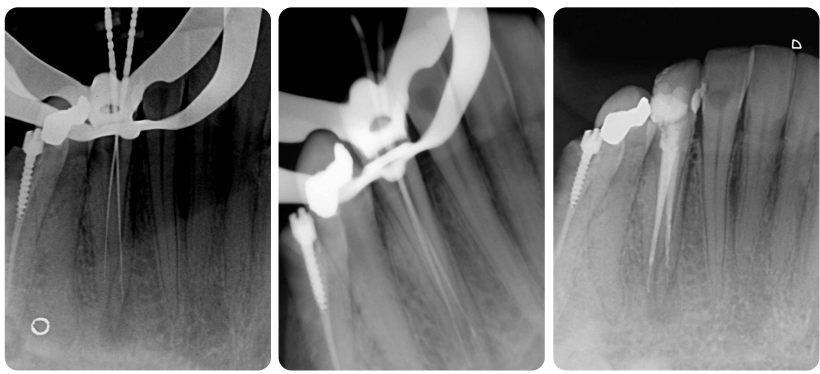

Figure 3: (a) Periapical radiograph of the mandibular canine showing the working length. (b) Master apical cone radiograph (c) Obturation

extended buccally. After successfully locating both orifices, chloroform was used carefully as solvent with $\mathrm{H}$-files to remove the previous gutta percha in the lingual canal. Upon negotiation the buccal canal, a size $8 \mathrm{~K}$-File was fractured but was bypassed. Working length of both canals was measured using an apex locator Root ZX II (J. Morita, Tokyo, Japan), and was confirmed radiographically [Figure 3a]. Instrumentation was done using step-back technique with hand files. K-files up to size 35 were used while irrigating with $1 \%$ sodium hypochlorite $(\mathrm{NaOCl})$ and $17 \%$ ethylenediaminetetraacetic acid (EDTA). Both canals were dried with paper points and master cone radiograph was taken [Figure 3b]. After the length of master apical cone was confirmed, obturation with gutta percha using cold lateral condensation and AH-Plus Sealer (Dentsply Maillefer, Ballaigues, Switzerland) was done [Figure 3c]. After the root canal treatment, the tooth was restored with composite and final radiograph was taken.

\section{DISCUSSION}

The inability to treat all the canals is one of the causes leading to endodontic failure. In a study by Hoen and Pink, it was found that the incidence of missed canals were reported to be $42 \%$ of all the 1100 endodontically failing teeth. ${ }^{6}$ Each tooth has a range of variation as reported in the literature.
The occurrence of two roots and two separate root canals in mandibular canine is rare and literature search has revealed $5 \%, 1 \%$ and $1.2 \%$ cases with two roots and two root canals respectively. ${ }^{7}$ The patient seen was a female and it was found that the incidence of two canals in mandibular canine was reported in female more than the male. ${ }^{8}$

Mandibular canines with two roots are more difficult to instrument and clean than single rooted canines. The long axis of the canal meets the crown surface at the incisal edge or on its labial surface. If this is not taken into consideration, it may lead to a preparation that is deviated. ${ }^{9}$ Versiani et al reported that in all two-rooted mandibular canines, the main apical foramen tends to be located eccentrically. Therefore, the possibility of overinstrumentation is high. ${ }^{10}$ Access cavity preparation can a challenging and frustrating part of endodontic treatment, but it is the key to successful treatment. That is why the majority of the problems that occur during the root canal treatment are due to the insufficient knowledge of the anatomy of the pulp space. The factors which were found most responsible for endodontic failures were underfilled canals (33.3\%) and unfilled and missed canals $(17.7 \%),{ }^{11}$ both which are seen in this case report. Radiography is an essential tool to successful diagnosis of odontogenic and nonodontogenic pathoses. Not only does it provide information on the morphology of the tooth including location and number of canals, but it also shows us the pulp chamber size and degree of calcification, root structure, direction and curvature, fractures, and the extent of dental caries. ${ }^{12}$ The image produced in a conventional intraoral radiograph is a two-dimensional representation of a three-dimensional object. Therefore when there is complex or unusual anatomy, it is best to take a CBCT. The most important advantage of CBCT in endodontics is that it demonstrates anatomic features in 3D that intraoral and panoramic images cannot. Another advantage is on-screen measurements are free from distortion and magnification. ${ }^{13}$ Clinicians should be able to study the anatomy in the preoperative radiograph and should be able to keep in mind the different anatomical variations seen. A good access cavity will help in detecting all the canals. These techniques combined with the use of magnification tools (magnification loupes or microscope) aid in the treatment. ${ }^{14}$ In addition, different angulated intraoral radiographs and CBCT could aid in diagnosis.

\section{CONCLUSION}

Although the presence of two roots in a mandibular canine is rare, the clinician should always keep in mind the different anatomical and morphological variations seen in canals and be able to diagnose before starting treatment for 
a successful outcome. With the help of CBCT, endodontic retreatment of mandibular canine with two separate roots was completed successfully.

\section{ACKNOWLEDGMENTS}

I would like to gratefully acknowledge Dr. Amal Almohaimede, our course director, not only for her guidance, support, and believing in her students, but also for her comments that greatly improved the manuscript. I would also like to thank for Dr. Raghad Basmael, my clinical instructor for this case, for her knowledge and clinical expertise.

\section{CONFLICT OF INTEREST}

None declared

\section{REFERENCES}

1. Abduo J, Tennant M, and Mcgeachie J, "Lateral occlusion schemes in natural and minimally restored permanent dentition: a systematic review," J Oral Rehabil. 2013;40:788-02.

https://doi.org/10.1111/joor.12095

2. Green D. Double canals in single roots. Oral Surg, Oral Medi, Oral Pathol. 1973;35:689-96. https://doi.org/10.1016/0030-4220(73)90037-6

3. Wang L, Zhang R, Peng B. Clinical features and treatment of mandibular canines with two root canals: Two case reports. Chinese J Dent Res. 2009;12:61-2.

4. Pecora JD, Sousaneto MD, Saquy PC, Internal anatomy,direction and number of root and size of human mandibular Canines Braz Dent J. 1993;4:53-7.

5. Sjögren U, Hägglund B, Sundqvist G, Wing K. Factors affecting the long-term results of endodontic treatment. J Endod. 1990;16:498504.

https://doi.org/10.1016/S0099-2399(07)80180-4

6. Hoen MM, Pink FE. Contemporary endodontic retreatments: An analysis based on clinical treatment findings. J Endod. 2002;28:834-36 https://doi.org/10.1097/00004770-200212000-00010

7. Victorino FR, Bernardes RA, Baldi JV, Moraes IG, Bernardinelli $\mathrm{N}$, Garcia RB, et al. Bilateral mandibular canines with two roots and two separate canals: case report. Braz Dent J. 2009;20:84-6 https://doi.org/10.1590/S0103-64402009000100015

8. Kaffe I, Kaufman A, Littner MM, Lazarson A. Radiographic study of the root canal system of mandibular anterior teeth. Int Endod J. 1985; 18:253-59.

https://doi.org/10.1111/j.1365-2591.1985.tb00452.x

9. Vipin Arora, Vineeta Nikhil, Jatin Gupta, Mandibular Canine with Two Root Canals - An Unusual Case Report, Int J of Stomatological Research. 2013; Vol. 2 No. 1, pp.1-4. https://doi.org.10.5923/j.ijsr.20130201.01

10. M. A. Versiani, J. D. Pécora, and M. D. Sousa-Neto, "The anatomy of two-rooted mandibular canines determined using micro-computed tomography," Int Endod J. 2011;vol. 44, no. 7, pp. 682-87 https://doi.org/10.1111/j.1365-2591.2011.01879.x

11. Iqbal A. The Factors Responsible for Endodontic Treatment Failure in the Permanent Dentitions of the Patients Reported to the College of Dentistry, the University of Aljouf, Kingdom of Saudi Arabia. J Clin Diag Res. 2016;10:ZC146-8. https://doi.org/10.7860/JCDR/2016/14272.7884

12. Walton RE. Diagnostic imaging A. endodontic radiography. In: Ingle JI, Bakland LK, Baumgartner JC, editors. Ingles' Endodontics.

13. Scarfe WC, Levin MD, Gane D, Farman AG. Use of cone beam computed tomography in endodontics. Int J Dent. 2010;2009:634567.

14. Carr GB. Microscopes in Endodontics. J Calif Dent Assoc. 1992;20:55-61. 